Article

\title{
Lactobacillus salivarius Subspecies salicinius SA-03 is a New Probiotic Capable of Enhancing Exercise Performance and Decreasing Fatigue
}

\author{
Mon-Chien Lee ${ }^{1}$, Yi-Ju Hsu ${ }^{1}$, Hsieh-Hsun Ho ${ }^{2}$, Shih-Hung Hsieh ${ }^{2}$, Yi-Wei Kuo ${ }^{2}$, \\ Hsin-Ching Sung ${ }^{3,4, *}$ and Chi-Chang Huang ${ }^{1, *}$ \\ 1 Graduate Institute of Sports Science, National Taiwan Sport University, No. 250, Wenhua 1st Rd., \\ Guishan District, Taoyuan City 33301, Taiwan; 1061304@ntsu.edu.tw (M.-C.L.); \\ ruby780202@ntsu.edu.tw (Y.-J.H.) \\ 2 Glac Biotech Co. Ltd., Tainan City 74442, Taiwan; sam.ho@glact.com.tw (H.-H.H.); \\ shih-hung.hsieh@glact.com.tw (S.-H.H.); vic.kuo@glact.com.tw (Y.-W.K.) \\ 3 Aesthetic Medical Center, Department of Dermatology, Chang Gung Memorial Hospital, \\ Taoyuan 33301, Taiwan \\ 4 Department of Anatomy, College of Medicine, Chang Gung University, No. 259, Wenhua 1st Rd., \\ Guishan Township, Taoyuan City, Taoyuan 33301, Taiwan \\ * Correspondence: hcs@mail.cgu.edu.tw (H.-C.S.); john5523@ntsu.edu.tw (C.-C.H.); \\ Tel.: +886-3-211-8800 (ext. 5977) (H.-C.S.); +886-3-328-3201 (ext. 2409) (C.-C.H.)
}

Received: 1 March 2020; Accepted: 7 April 2020; Published: 9 April 2020

\begin{abstract}
Probiotics are increasingly being used as a nutritional supplement by athletes to improve exercise performance and reduce post-exercise fatigue. Lactobacillus salivarius is a natural flora in the gastrointestinal tract of humans and animals. Lactobacillus salivarius subspecies salicinius (SA-03) is an isolate from the 2008 Olympic women's $48 \mathrm{~kg}$ weightlifting gold medalist's gut microbiota. In this study, we investigated its beneficial effects on physical fitness. Male ICR mice were divided into four groups ( $n=10$ per group) and orally administered with SA-03 for 4 weeks at $0,2.05 \times 10^{9}, 4.10 \times 10^{9}$, or $1.03 \times 10^{10} \mathrm{CFU} / \mathrm{kg} /$ day. Results showed that 4 weeks of SA-03 supplementation significantly improved muscle strength and endurance performance, increased hepatic and muscular glycogen storage, and decreased lactate, blood urea nitrogen (BUN), ammonia, and creatine kinase (CK) levels after exercise. These observations suggest that SA-03 could be used as a nutritional supplement to enhance exercise performance and reduce.
\end{abstract}

Keywords: probiotic; SA-03; Lactobacillus; nutritional supplement; exercise performance; weightlifting

\section{Introduction}

Non-pathological / physiological fatigue can be further characterized as being caused by central and peripheral mechanisms, and both of these mechanisms play important roles in the physiological effects of exercise process, type, intensity, and duration [1,2]. During prolonged endurance exercise, the energy resources required by muscles are insufficient to maintain and produce the same level of strength, causing fatigue reactions and decrease exercise performance [3]. As people become more interested in the gut microbiota a relationship with exercise performance was found. Gut microbiota can ferment dietary fiber to short-chain fatty acids (SCFA) as an energy source for liver and muscle cells and improve endurance performance through stable blood glucose regulation. In addition, SCFA seems to be able to reduce the permeability of colonic mucosa by regulating the function and metastasis of neutrophils, inhibiting inflammatory cytokines and reducing the redox response, which is one of the possible factors to reduce fatigue $[4,5]$. 
In recent years, sports nutrition supplements are considered as necessary for increasing exercise performance or reducing post-exercise fatigue and have played an important role in scientific exercise training. In addition to traditional herbs, proteins and creatine, probiotics have also received increasing attention as dietary supplements. According to the World Health Organization, Food and Agriculture Organization of the United Nations (WHO/FAO) definition, probiotics are live microorganisms, not causing any adverse effects on the organism and providing health benefits when administered in appropriate amounts [6]. Previous studies have shown that probiotics have anti-obesity effects [7], can lower cholesterol levels [8], anti-inflammation [9], anti-bacterial [10], anti-oxidation [11], anti-proliferative and anti-carcinogenic activities [12]. They have also been shown to enhance carbohydrate metabolism to produce SCFA [13] such as butyrate, which is then converted to acetyl-CoA for production of adenosine triphosphate (ATP) to provide energy [14]. Therefore, past research has shown that, probiotic supplements can effectively improve exercise performance and reduce fatigue biochemical values after exercise $[15,16]$.

The name Lactobacillus salivarius derives from the characteristic "saliva" of the oral cavity, from which it was isolated for the first time [17]. Research findings in recent years have shown that $L$. salivarius is commonly found in the gastrointestinal tract of humans and animals. The genomic structure of $L$. salivarius was first derived from the UCC118 chromosome. The strain's genome consists of a $1.83 \mathrm{Mb}$ chromosome, a large $242 \mathrm{~kb}$ plasmid, and two smaller plasmids [18]. Its genomic diversity has recently been well evaluated and has been studied as a candidate probiotic. [19]. Preliminary studies have described the species' immunomodulatory properties in cell lines, mice, rats, and humans to eliminate diseases in the body and promote host health. The ability of L. salivarius to suppress the resistance of pathogens and hosts to antibacterial defense demonstrates the adaptability of the species' hormone niche [20]. Previous studies have shown that $L$. salivarius supplementation reduces exercise-induced gastrointestinal permeability and remodels the gut microbiome in healthy humans [21], however, the evolutionary species and subspecies of different strains have different functional characteristics. Emerging research on the probiotic potential of this species remains to be discussed in detail.

Lactobacillus salivarius subsp. salicinius (SA-03), a human-origin probiotic was isolated from a female weightlifter's gut microbiota. In this study, we evaluated the function and efficacy of SA-03 supplements through exercise testing and analysis of fatigue-related biochemical indicators, and confirmed that it would not cause adverse damage in mice.

\section{Materials and Methods}

\subsection{Lactobacillus salivarius subsp. salicinius (SA-03) Preparation}

Lactobacillus salivarius SA-03 was isolated from the 2008 Olympic women's $48 \mathrm{~kg}$ weightlifting gold medalist's gut microbiota. The isolate was confirmed to be Lactobacillus salivarius by the Food Industry Research and Development Institute (Hsinchu, Taiwan). The dry product of SA-03 was prepared and provided by Glac Biotech Co., Ltd. (Tainan City, Taiwan). Viable cell counts of SA-03 were $1.07 \times 10^{11} \mathrm{CFU} / \mathrm{g}$. The powder was suspended in phosphate buffered saline (PBS, pH 7.2) before consumption.

\subsection{Animals and Experimental Design}

Pathogen-free male 6-week-old ICR mice were purchased from BioLASCO (Yi-Lan, Taiwan). All animal experiments were approved by the Institutional Animal Care and Use Committee (IACUC) of National Taiwan Sport University. Mice were maintained at a 12-h light/dark cycle at room temperature $\left(23 \pm 2{ }^{\circ} \mathrm{C}\right)$ and $50-60 \%$ humidity and provided with reverse osmosis (R.O) water and standard chow diet (No. 5001; PMI Nutrition International, Brentwood, MO, USA) ad libitum.

As probiotics are being used in humans at a daily dose of $1 \times 10^{10}$ live bacteria [22], the dose given to mice was converted from the human equivalent dose (HED) based on the surface area of human body. Accordingly, mice were divided into four treatment groups (a total of three cages per 
group, each containing 3-4 mice per cage, 10 mice total per group): (1) vehicle group (0 CFU/kg); (2) SA-03-1X group (2.05 $\left.\times 10^{9} \mathrm{CFU} / \mathrm{kg}\right)$; (3) SA-03-2X group $\left(4.10 \times 10^{9} \mathrm{CFU} / \mathrm{kg}\right)$, and (4) SA-03-5X group $\left(1.03 \times 10^{10} \mathrm{CFU} / \mathrm{kg}\right)$. All mice were administered by gavage the same volume of SA-03 suspension or PBS daily for 4 weeks.

\subsection{Swimming Exercise Endurance Test}

The swim-to-exhaustion exercise test was performed as previously described [23]. A weight equivalent to $5 \%$ of body weight (BW) was loaded on the tail of the test mouse. The test mouse was then forced to swim until loss of coordinated movements or failure to return to the surface within $7 \mathrm{~s}$ [24], and the duration of such swimming was recorded.

\subsection{Forelimb Grip Strength}

A low-force testing system (Model-RX-5, Aikoh Engineering, Nagoya, Japan) with a tension rod (diameter $2 \mathrm{~mm}$, length $7.5 \mathrm{~cm}$ ) and force sensor was used to measure the grip strength of mice as described previously [25].

\subsection{Determination of Fatigue-Associated Biochemical Variables}

As previous reports [26], post-exercise assessment of the effects of supplementation SA-03 on fatigue-related biochemical indicators, and accurate display and assessment of physiological status. Fatigue-related variables were measured under fasting conditions to reflect actual physiological fitness. under exercise. intervention. Blood samples were collected after $10 \mathrm{~min}$ of swimming and $20 \mathrm{~min}$ of rest. The samples were centrifuged at $1500 \mathrm{xg}$ for $15 \mathrm{~min}$ at $4{ }^{\circ} \mathrm{C}$, and serum was collected to analyzed. The Serum levels of lactic acid, ammonia $\left(\mathrm{NH}_{3}\right)$, and glucose levels were measured by with an automatic analyzer (model 7060, Hitachi, Tokyo, Japan). Other variables, such as blood urine nitrogen (BUN) and creatine kinase (CK), were evaluated immediately after $90 \mathrm{~min}$ of extended exercise and $60 \mathrm{~min}$ of rest.

\subsection{Resting Biochemical Profiles at the End of the Study}

One hour after the last swimming endurance test, all mice were euthanized by $95 \% \mathrm{CO} 2$ asphyxiation, and blood was obtained by cardiac puncture at the end of the study. Serum was collected after centrifugation and biochemical indexes assessed by a Hitachi 7060 autoanalyzer. Levels of aspartate aminotransferase (AST), alanine transaminase (ALT), albumin (ALB), total protein (TP), BUN, creatinine (CREA), uric acid (UA), total cholesterol (TC), triglycerides (TG), creatine kinase (CK), and glucose (GLU) were measured with the aforementioned autoanalyzer.

\subsection{Body Composition, Glycogen Content, and Histopathology}

After being euthanized, the liver, kidneys, heart, lungs, muscles, epididymal fat pad (EFP), and brown adipose tissue (BAT) of mice were excised, weighed, and processed for histological examinations. Tissue sections were stained with hematoxylin and eosin $(\mathrm{H} \& \mathrm{E})$ and examined by a clinical pathologist. Muscle and liver tissues were also processed for determination of glycogen content.

\subsection{Bacterial DNA Extraction and $16 S$ rRNA Sequencing}

According to the method previously used in our laboratory, immediately after euthanizing the mice, the collected samples were stored at $-80^{\circ} \mathrm{C}$ for DNA extraction. Detailed procedures for sample extraction, preparation and analysis have been previously described [16].

\subsection{Statistical Analysis}

All statistical analyses were performed with SAS 9.4 (SAS Institute, Cary, NC, USA). One-way analysis of variance (ANOVA) was used to determine significant difference among groups. 
The Cochran-Armitage test was used for dose-effect trend analyses. Data are expressed as mean \pm SD. $p<0.05$ was considered as significant.

\section{Results}

\subsection{Effect of SA-03 Supplementation on Body Weight, Body Composition, and Food and Water Intake}

There was no significant difference in average body weight of mice among the 4 different dosing groups at different time points during the four weeks of SA-03 supplementation. (Figure 1). There was also no significant difference in food and water intake and various parameters among the four groups (Table 1).

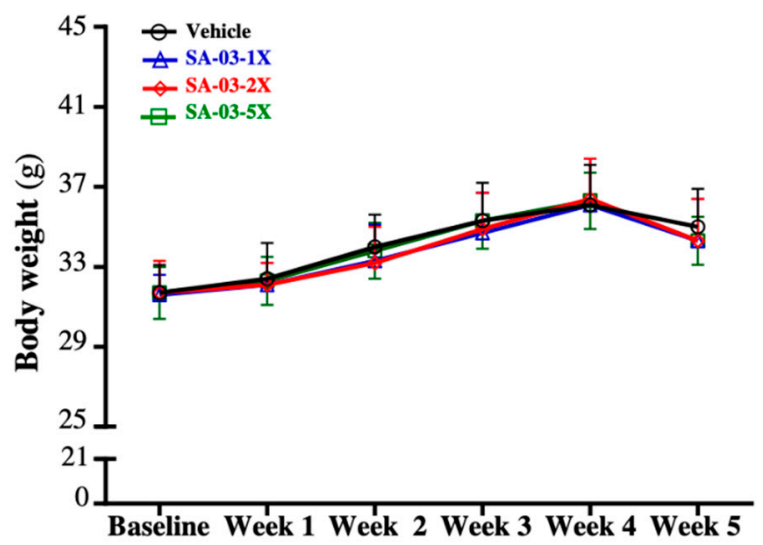

Figure 1. Effect of SA-03 supplementation on body weight of mice. Data are expressed as mean \pm SD for $n=10$ mice per group.

Table 1. Effect of SA-03 supplementation on various parameters.

\begin{tabular}{|c|c|c|c|c|c|}
\hline Characteristic & Vehicle (PBS) & SA-03-1X & SA-03-2X & SA-03-5X & Trend Analysis \\
\hline Initial BW (g) & $31.7 \pm 1.4$ & $31.6 \pm 1.0$ & $31.7 \pm 1.6$ & $31.7 \pm 1.3$ & 0.8686 \\
\hline Final BW (g) & $36.8 \pm 2.2$ & $36.4 \pm 2.1$ & $36.1 \pm 2.3$ & $35.9 \pm 1.7$ & 0.6070 \\
\hline Water intake (mL/mouse/day) & $7.6 \pm 0.5$ & $7.3 \pm 0.9$ & $7.2 \pm 0.9$ & $7.4 \pm 1.0$ & 0.1138 \\
\hline Food intake (g/mouse/day) & $8.8 \pm 1.7$ & $9.2 \pm 1.2$ & $9.0 \pm 1.4$ & $8.9 \pm 1.9$ & 0.6364 \\
\hline Liver $(g)$ & $1.86 \pm 0.19$ & $1.83 \pm 0.22$ & $1.89 \pm 0.25$ & $1.82 \pm 0.11$ & 0.7169 \\
\hline Muscle (g) & $0.37 \pm 0.03$ & $0.37 \pm 0.03$ & $0.36 \pm 0.04$ & $0.37 \pm 0.03$ & 0.4901 \\
\hline Quadriceps (g) & $0.48 \pm 0.05$ & $0.49 \pm 0.05$ & $0.47 \pm 0.04$ & $0.49 \pm 0.04$ & 0.8718 \\
\hline Kidney (g) & $0.65 \pm 0.09$ & $0.66 \pm 0.06$ & $0.62 \pm 0.03$ & $0.62 \pm 0.06$ & 0.2541 \\
\hline Heart (g) & $0.18 \pm 0.03$ & $0.18 \pm 0.02$ & $0.18 \pm 0.02$ & $0.18 \pm 0.04$ & 0.2773 \\
\hline Lung (g) & $0.23 \pm 0.03$ & $0.23 \pm 0.03$ & $0.23 \pm 0.03$ & $0.23 \pm 0.04$ & 0.1584 \\
\hline $\operatorname{EFP}(g)$ & $0.32 \pm 0.10$ & $0.31 \pm 0.07$ & $0.31 \pm 0.07$ & $0.31 \pm 0.06$ & 0.7057 \\
\hline BAT (g) & $0.09 \pm 0.02$ & $0.08 \pm 0.03$ & $0.09 \pm 0.02$ & $0.09 \pm 0.02$ & 0.4066 \\
\hline Cecum (g) & $0.85 \pm 0.07$ & $0.88 \pm 0.14$ & $0.83 \pm 0.13$ & $0.88 \pm 0.10$ & 0.8411 \\
\hline * Relative liver weight (\%) & $5.03 \pm 0.25$ & $5.04 \pm 0.74$ & $5.23 \pm 0.61$ & $5.07 \pm 0.17$ & 0.5428 \\
\hline Relative muscle weight (\%) & $1.01 \pm 0.09$ & $1.01 \pm 0.04$ & $1.01 \pm 0.10$ & $1.02 \pm 0.07$ & 0.9060 \\
\hline Relative quadriceps weight (\%) & $1.31 \pm 0.14$ & $1.34 \pm 0.11$ & $1.30 \pm 0.10$ & $1.35 \pm 0.07$ & 0.5903 \\
\hline Relative kidney weight (\%) & $1.76 \pm 0.20$ & $1.82 \pm 0.11$ & $1.73 \pm 0.12$ & $1.72 \pm 0.18$ & 0.4407 \\
\hline Relative heart weight (\%) & $0.50 \pm 0.08$ & $0.50 \pm 0.04$ & $0.51 \pm 0.09$ & $0.51 \pm 0.12$ & 0.4467 \\
\hline Relative lung weight (\%) & $0.63 \pm 0.08$ & $0.63 \pm 0.08$ & $0.63 \pm 0.07$ & $0.64 \pm 0.10$ & 0.1420 \\
\hline Relative EFP weight (\%) & $0.87 \pm 0.24$ & $0.84 \pm 0.18$ & $0.87 \pm 0.23$ & $0.86 \pm 0.17$ & 0.6941 \\
\hline Relative BAT weight (\%) & $0.25 \pm 0.06$ & $0.22 \pm 0.08$ & $0.25 \pm 0.05$ & $0.26 \pm 0.06$ & 0.3942 \\
\hline Relative cecum weight (\%) & $2.31 \pm 0.19$ & $2.43 \pm 0.34$ & $2.29 \pm 0.38$ & $2.46 \pm 0.33$ & 0.3665 \\
\hline
\end{tabular}

Data are expressed as mean \pm SD ( $n=10$ mice per group). EFP: epididymal fat pad; BAT: brown adipose tissue.

* Relative to body weight. 


\subsection{Effect of SA-03 Supplementation on Endurance Capacity}

The average exhaustive swim time of mice in vehicle, SA-03-1X, SA-03-2X, and SA-03-5X groups was $7.29 \pm 0.95,11.86 \pm 1.19,14.37 \pm 1.30$, and $20.15 \pm 2.21 \mathrm{~min}$, respectively (Figure 2). Compared to the vehicle group, the average exhaustive swim time of SA-03-1X, SA-03-2X, and SA-03-5X groups was increased by 1.63-fold $(p<0.0001), 1.97$-fold $(p<0.0001)$, and 2.76-fold $(p<0.0001)$, respectively after four weeks of SA-03 supplementation. Results of trend analyses showed that the effect of SA-03 supplementation on maximum swim time was dose dependent $(p<0.0001)$.

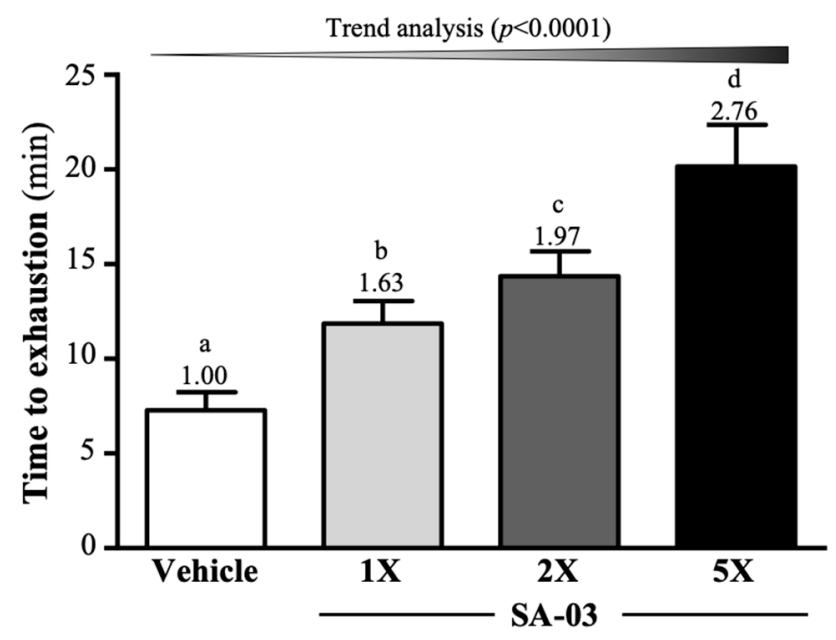

Figure 2. Effect of four weeks of SA-03 supplementation on exhaustive swim time. Data are expressed as mean $\pm \mathrm{SD}(n=10$ mice per group). Different superscript letters $(\mathrm{a}, \mathrm{b}, \mathrm{c}, \mathrm{d})$ indicate significant difference $(p<0.05)$.

\subsection{Effect of SA-03 Supplementation on Grip Strength}

The mean forelimb grip strengths of mice in vehicle, SA-03-1X, SA-03-2X, and SA-03-5X groups were $122 \pm 5,140 \pm 6,143 \pm 6$, and $151 \pm 4 \mathrm{~g}$ (Figure 3A), respectively after 4 weeks of SA-03 supplementation. This represented a 1.15-fold $(p<0.0001), 1.17$-fold $(p<0.0001)$, and 1.23-fold $(p<0.0001)$ increase in grip strength of mice in the three treatment groups, respectively, compared to mice in the vehicle group. Relative grip strength (\%), normalized to body weight, was also significantly higher in groups with SA-03 supplementation (Figure 3B). The effect of SA-03 supplementation on both absolute and relative grip strength was dose dependent (trend analysis, $p<0.0001$ ).

(A)

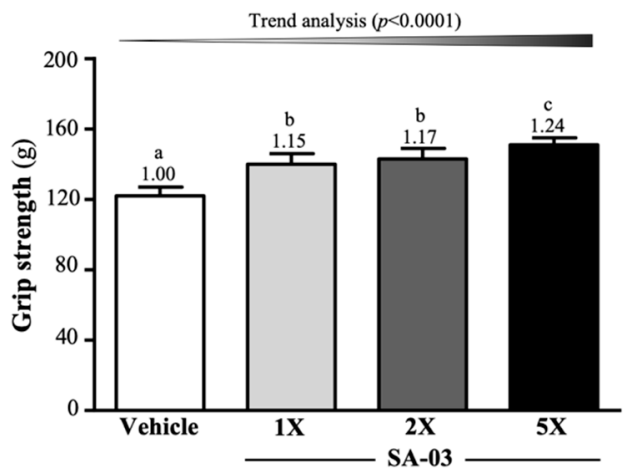

(B)

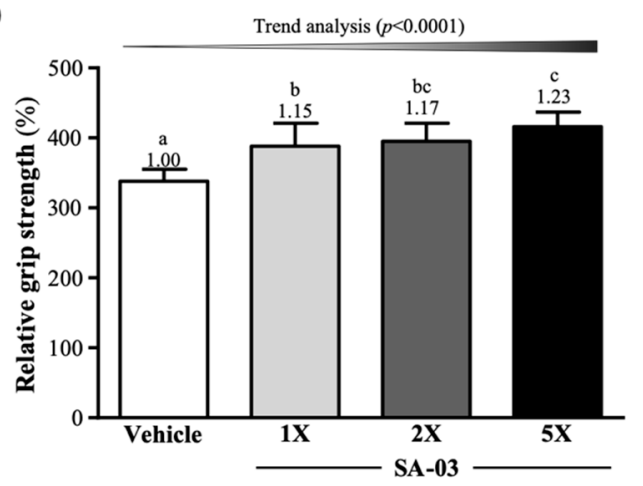

Figure 3. Effect of four weeks of SA-03 supplementation on (A) absolute forelimb grip strength and (B) forelimb grip strength (\%) relative to body weight. Data are expressed as mean \pm SD $(n=10$ mice per group). Different superscript letters $(a, b, c)$ indicate significant difference $(p<0.05)$. 


\subsection{Effect of SA-03 Supplementation on Serum Lactate Levels after the 10-Min Swim Test}

After 4 weeks of SA-03 supplementation, mice were subjected to the 10-min swimming test and assessed for serum lactate levels at three time points: pre-exercise, post-exercise, and $20 \mathrm{~min}$ after resting (Table 2). Before swimming, there was no significant difference in the levels of serum lactate among the four groups. After $10 \mathrm{~min}$ of swimming, serum lactate levels of mice in vehicle, SA-03-1X, SA-03-2X, and SA-03-5X groups were $8.73 \pm 0.65,7.53 \pm 0.90,6.65 \pm 0.85$, and $4.53 \pm 0.89 \mathrm{mmol} / \mathrm{L}$, respectively. This result indicated a decrease of $13.80 \%(p=0.0012), 23.89 \%(p<0.0001)$, and $33.77 \%(p<0.0001)$ in serum lactate levels in SA-03-1X, SA-03-2X, and SA-03-5X groups, respectively, compared to the vehicle group. Based on serum lactic acid concentration before and after $10 \mathrm{~min}$ of swimming, the lactate production rates were determined to be $2.64 \pm 0.47,2.30 \pm 0.41,2.13 \pm 0.57$ and $1.68 \pm 0.30$, respectively in vehicle, SA-03-1X, SA-03-2X, and SA-03-5X groups. Compared to the vehicle group, the lactate production rate of mice in the SA-03-2X group was decreased by $19.17 \%(p=0.0156)$ and that of mice in the SA-03-5X group was decreased by $36.47 \%(p<0.0001)$ after four weeks of SA-03 supplementation.

Table 2. Effect of SA-03 on lactate levels.

\begin{tabular}{cccccc}
\hline \multirow{2}{*}{ Time Point } & Vehicle & SA-03-1X & SA-03-2X & SA-03-5X & Trend Analysis \\
\cline { 2 - 5 } & \multicolumn{5}{c}{ Lactate (mmol/L) } \\
\hline Before swimming (A) & $3.41 \pm 0.69$ & $3.34 \pm 0.56$ & $3.30 \pm 0.85$ & $3.50 \pm 0.37$ & 0.6087 \\
After swimming (B) & $8.73 \pm 0.65^{\mathrm{d}}$ & $7.53 \pm 0.90^{\mathrm{c}}$ & $6.65 \pm 0.85^{\mathrm{b}}$ & $5.78 \pm 0.64^{\mathrm{a}}$ & $<0.0001$ \\
After 20 min resting (C) & $6.84 \pm 0.48^{\mathrm{c}}$ & $5.85 \pm 1.08^{\mathrm{b}}$ & $5.40 \pm 0.71^{\mathrm{b}}$ & $4.53 \pm 0.89^{\mathrm{a}}$ & $<0.0001$ \\
\hline \multicolumn{7}{c}{ Rate of lactate production and clearance $^{\mathrm{c}}$} \\
\hline Production rate = B/A & $2.64 \pm 0.47^{\mathrm{c}}$ & $2.30 \pm 0.41^{\mathrm{b}, \mathrm{c}}$ & $2.13 \pm 0.57^{\mathrm{b}}$ & $1.68 \pm 0.30^{\mathrm{a}}$ & $<0.0001$ \\
Clearance rate = (B-C)/B & $0.21 \pm 0.07^{\circ}$ & $0.22 \pm 0.10$ & $0.19 \pm 0.08$ & $0.22 \pm 0.11$ & 0.9901 \\
\hline
\end{tabular}

Lactate production rate $(\mathrm{B} / \mathrm{A})$ was the value of the lactate level after exercise (B) divided by that before exercise (A). Clearance rate $(\mathrm{B}-\mathrm{C}) / \mathrm{B}$ was defined as lactate level after swimming $(\mathrm{B})$ minus that after 20 min rest $(\mathrm{C})$ divided by that after swimming (B). Data are expressed as mean $\pm \mathrm{SD}(n=10$ mice per group). Values in the same row with different superscript letters $(\mathrm{a}, \mathrm{b}, \mathrm{c}, \mathrm{d})$ differ significantly, $p<0.05$.

After $20 \mathrm{~min}$ of resting following the swimming test, serum lactate levels of mice in vehicle, SA-03-1X, SA-03-2X, and SA-03-5X groups were $6.84 \pm 0.48,5.85 \pm 1.08,5.40 \pm 0.71$, and $4.53 \pm 0.89 \mathrm{mmol} / \mathrm{L}$, respectively. The levels of mice in the three treatment groups were $14.56 \%$ $(p=0.0099), 21.16 \%(p=0.0003)$, and $33.76 \%(p<0.0001)$, respectively, lower than those of mice in the vehicle group. The effect of SA-03 supplementation on serum lactate levels was also dose dependent.

\subsection{Effect of SA-03 Supplementation on Serum Glucose and Ammonia Levels after the 10 Min Swim Test}

As shown in Figure 4A, serum glucose levels of mice after $10 \mathrm{~min}$ of swimming in vehicle, SA-03-1X, SA-03-2X, and SA-03-5X groups were $102 \pm 8,115 \pm 12,116 \pm 10$, and $120 \pm 9(\mathrm{mg} / \mathrm{dL})$. The levels of the three treatment groups were 1.12-fold ( $p=0.0098), 1.14$-fold $(p=0.0035)$, and 1.17-fold $(p=0.0004)$ that of the vehicle group, respectively. Serum ammonia levels of mice in vehicle, SA-03-1X, SA-03-2X, and SA-03-5X groups were $105 \pm 6,95 \pm 10,95 \pm 4$, and $96 \pm 4(\mu \mathrm{mol} / \mathrm{L})$, respectively, and the levels of the three treatment groups were $10.08 \%(p=0.0010), 9.60 \%(p=0.0015)$, and $8.46 \%(p=0.0046)$ lower than that of the vehicle group, respectively.

\subsection{Effect of SA-03 Supplementation on Serum BUN and CK Levels after 90 Min Swimming and 60 Min Rest}

To study the anti-fatigue effect of SA-03, serum BUN levels were measured 60 min after the 90-min swimming test (Figure 5A). Serum BUN levels were found to be $35.5 \pm 4.5,35.3 \pm 3.9,31.8 \pm 4.0$, and $29.8 \pm 3.4 \mathrm{mg} / \mathrm{dL}$ in mice in vehicle, SA-03-1X, SA-03-2X, and SA-03-5X groups, respectively. This result indicated that exercise-induced BUN was decreased by $10.61 \%(p=0.0416)$ in mice in the SA-03-2X group and $16.16 \%(p=0.0027)$ in those in the SA-03-5X groups. 
(A)

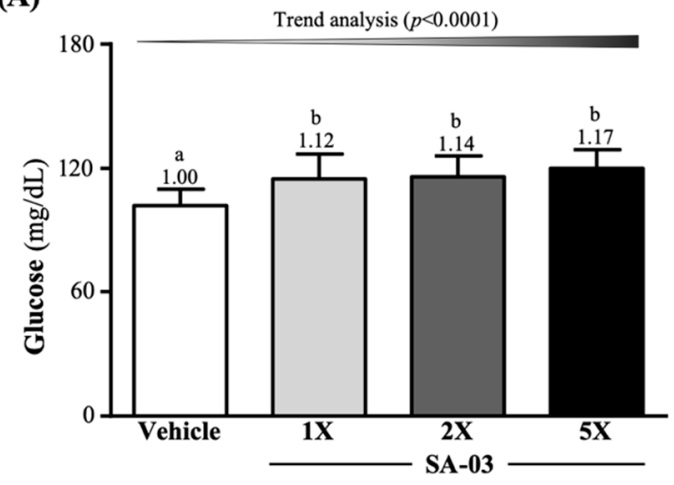

(B)

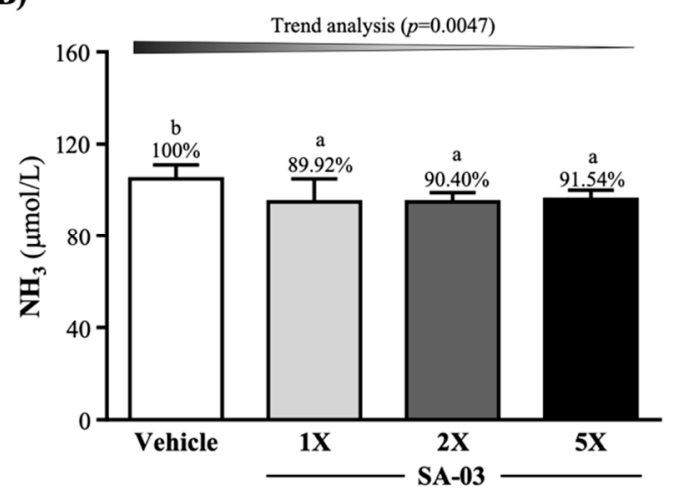

Figure 4. Effect of 4 weeks of SA-03 supplementation on serum (A) glucose and (B) ammonia $\left(\mathrm{NH}_{3}\right)$ levels after 10 min of swimming. Data are expressed as mean $\pm \mathrm{SD}(n=10$ mice per group). Different superscript letters $(a, b)$ indicate significant difference $(p<0.05)$.

(A)

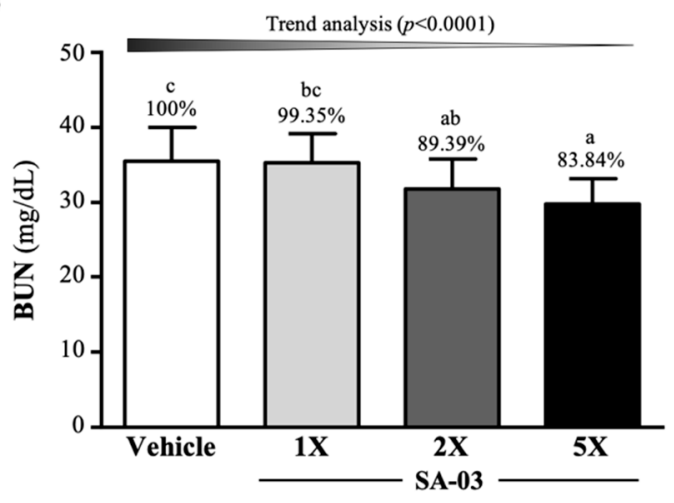

(B)

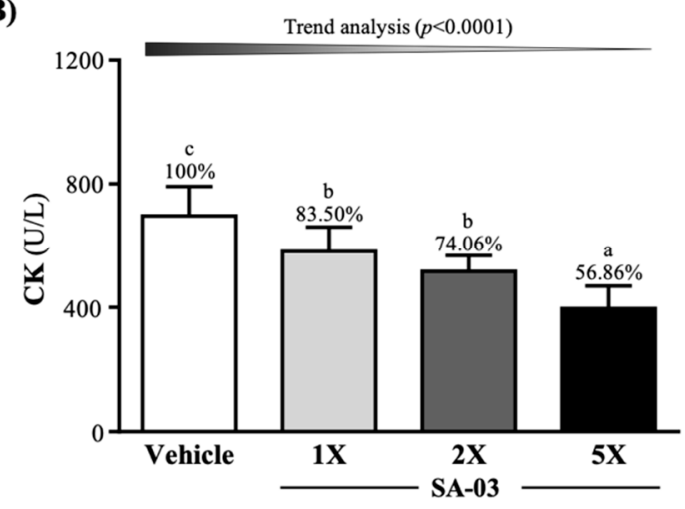

Figure 5. Effect of 4 weeks of SA-03 supplementation on serum (A) BUN and (B) CK levels after 90-min swimming exercise and 60-min rest. Data are expressed as mean $\pm \mathrm{SD}(n=10$ mice per group). Different superscript letters $(\mathrm{a}, \mathrm{b}, \mathrm{c})$ indicate significant difference at $p<0.05$.

CK levels, an exercise injury index, were found to be decreased by $16.50 \%(p=0.0019), 25.94 \%$ $(p<0.0001)$, and 43.14\% $(p<0.0001)$, respectively, in SA-03-1X, SA-03-2X, and SA-03-5X groups compared to the vehicle control group.

\subsection{Effect of SA-03 Supplementation on Liver and Muscle Glycogen Levels}

Liver glycogen levels of mice in vehicle, SA-03-1X, SA-03-2X, and SA-03-5X groups were $26.32 \pm 3.14,29.33 \pm 5.83,31.35 \pm 3.82$, and $36.69 \pm 3.69 \mathrm{mg} / \mathrm{g}$ of liver, respectively and were elevated by 1.19 -fold $(p=0.0120)$ in the SA-03-2X group and 1.39-fold $(p<0.0001)$ in the SA-03-5X group compared to the vehicle group (Figure 6A). Muscle glycogen levels in vehicle, SA-03-1X, SA-03-2X, and SA-03-5X groups were $1.58 \pm 0.24,2.00 \pm 0.33,1.99 \pm 0.41,2.19 \pm 0.32 \mathrm{mg} / \mathrm{g}$ of muscle, representing an increase of 1.26 -fold ( $p=0.0084), 1.26$-fold $(p<0.0098)$, and 1.38-fold $(p=0.0002)$ in the three treatment groups, respectively (Figure 6B). The effect of SA-03 supplementation on hepatic and muscular glycogen content was also dose dependent $(p<0.0001)$.

\subsection{Effect of SA-03 Supplementation on Biochemical Profiles}

The effect of SA-03 supplementation on biochemical parameters were also evaluated (Table 3). The levels of liver damage markers (AST and ALT) and mean levels of albumin, TC, TG, CK, BUN, creatinine, UA, TP, and glucose were found to be similar among the groups $(p>0.05)$. This observation suggests that SA-03 has no adverse effects on health. 
(A)

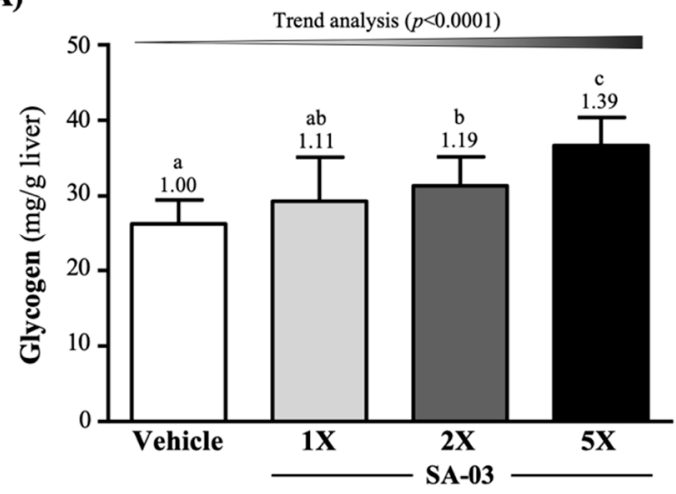

(B)

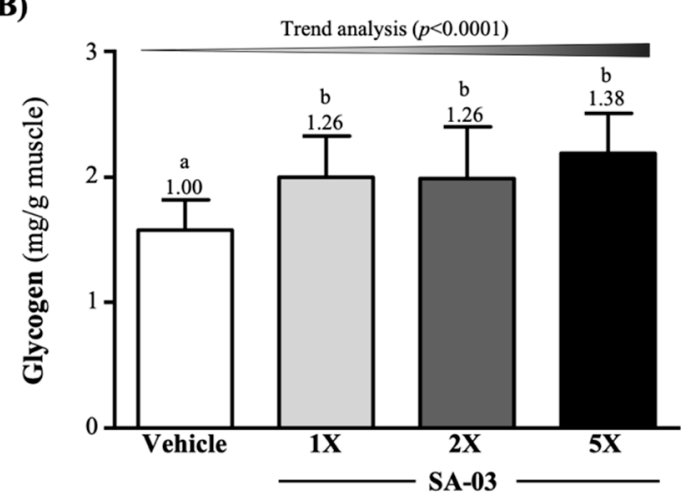

Figure 6. Effect of 4 weeks of SA-03 supplementation on (A) hepatic and (B) muscle glycogen levels. Data are expressed as mean \pm SD for $n=10$ mice per group. Values with different superscript letters $(\mathrm{a}, \mathrm{b}, \mathrm{c})$ are significantly different at $p<0.05$.

Table 3. Effects of SA-03 on biochemical parameters.

\begin{tabular}{cccccc}
\hline Parameter & Vehicle & SA-03-1X & SA-03-2X & SA-03-5X & Trend Analysis \\
\hline AST (U/L) & $67 \pm 9$ & $69 \pm 6$ & $67 \pm 9$ & $67 \pm 9$ & 0.7926 \\
ALT (U/L) & $36 \pm 8$ & $34 \pm 9$ & $34 \pm 8$ & $30 \pm 6$ & 0.0367 \\
CK (U/L) & $162 \pm 30$ & $165 \pm 24$ & $159 \pm 16$ & $162 \pm 22$ & 0.3890 \\
GLU (mg/dL) & $186 \pm 14$ & $186 \pm 11$ & $187 \pm 14$ & $187 \pm 15$ & 0.8841 \\
CREA (mg/dL) & $0.41 \pm 0.02$ & $0.42 \pm 0.03$ & $0.42 \pm 0.02$ & $0.42 \pm 0.03$ & 0.3146 \\
BUN (mg/dL) & $21.4 \pm 3.0$ & $21.4 \pm 2.0$ & $21.1 \pm 1.9$ & $21.3 \pm 1.8$ & 0.9156 \\
UA (mg/dL) & $1.7 \pm 0.2$ & $1.7 \pm 0.2$ & $1.7 \pm 0.2$ & $1.7 \pm 0.3$ & 0.9649 \\
TC (mg/dL) & $147 \pm 22$ & $147 \pm 20$ & $147 \pm 16$ & $147 \pm 16$ & 0.9617 \\
TG (mg/dL) & $156 \pm 22$ & $156 \pm 19$ & $156 \pm 21$ & $154 \pm 21$ & 0.7516 \\
ALB (g/dL) & $3.0 \pm 0.1$ & $3.0 \pm 0.3$ & $3.0 \pm 0.3$ & $3.0 \pm 0.2$ & 0.9723 \\
TP (g/dL) & $5.6 \pm 0.3$ & $5.7 \pm 0.4$ & $5.7 \pm 0.3$ & $5.6 \pm 0.3$ & 0.9616 \\
\hline
\end{tabular}

Data are expressed as mean $\pm \mathrm{SD}(n=10$ mice per group). AST, aspartate aminotransferase; ALT, alanine transaminase; CK, creatine kinase; GLU, glucose; CREA, creatinine; BUN, blood urea nitrogen; UA, uric acid; TC, total cholesterol; TG, triacylglycerol; ALB, albumin; TP, total protein.

\subsection{Effect of SA-03 Supplementation on the Gut Microbiota}

We analyzed the gut microbiota composition using the $16 \mathrm{~S}$ rRNA Genes in the vehicle or SA-03treated mice and observed dramatic changes in the microbial ecology when treated with SA-03 at the end of experiment. As shown in Figure 7A, the number of Lactobacillus, Bifidobacterium, Enterococcus, Akkermania, and Lactococcus in SA-03 supplementation were all richer than vehicle at the level of microbiota, especially in the Lactobacillus (Figure 7B), Bifidobacterium (Figure 7C) and Akkermania (Figure 7D), the ratio of SA-03-2X and 5X were significantly richer $(p<0.05)$. In addition, among the human harmful gut microbiota, the Clostridium, Helicobacter, Escherichia, and Listeria was lower in the SA-03-5X group than vehicle group, especially Helicobacter (Figure 7E) was significantly lower $(p<0.05)$.

In Species (Figure 8A), the number of Lactobacillu in SA-03 supplementation of mice were total increase, among them, Lactobacillus salivarius, Lactobacillus reuteri, Lactobacillus vaginalis, and Lactobacillus antri were more abundant than the vehicle group. In comparison, the percentage changes of Lactobacillus species in SA-03-1X, SA-03-2X and SA-03-5X were $4.23 \%, 9.07 \%$, and $16.55 \%$, respectively. 
(A)

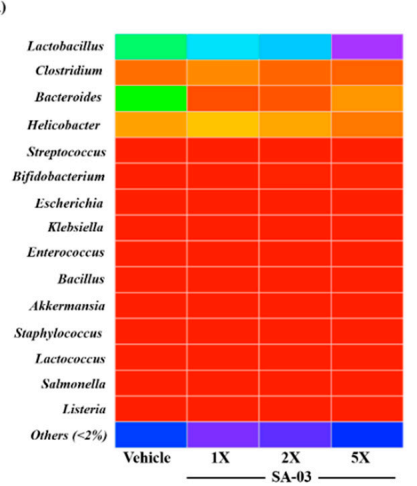

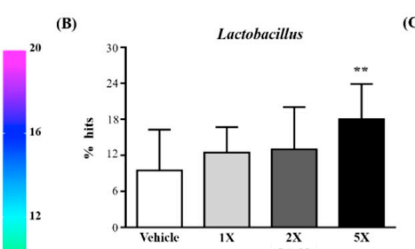

(D)

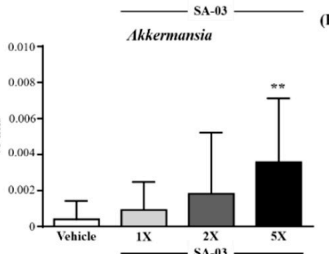

(C)

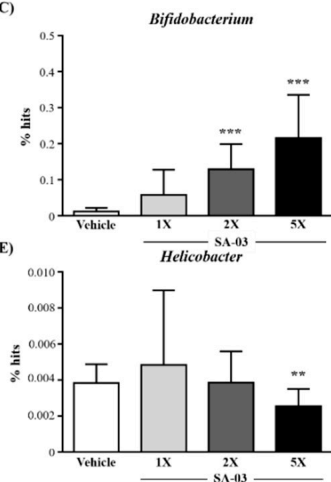

Figure 7. Effect of 4 weeks of SA-03 supplementation on (A) Genus heatmap of gut microbiota, (B) Lactobacillus \% hit, (C) Bifidobacterium \% hit, (D) Akkermania \% hit and (E) Helicobacter \% hit. Data are expressed as mean $\pm \mathrm{SD}$ for $n=9$ mice per group. Values with different superscript letters are significantly different at ${ }^{*}, p<0.05 ; * *, p<0.05 ; * * *, p<0.05$ by $t$-test.

(A)
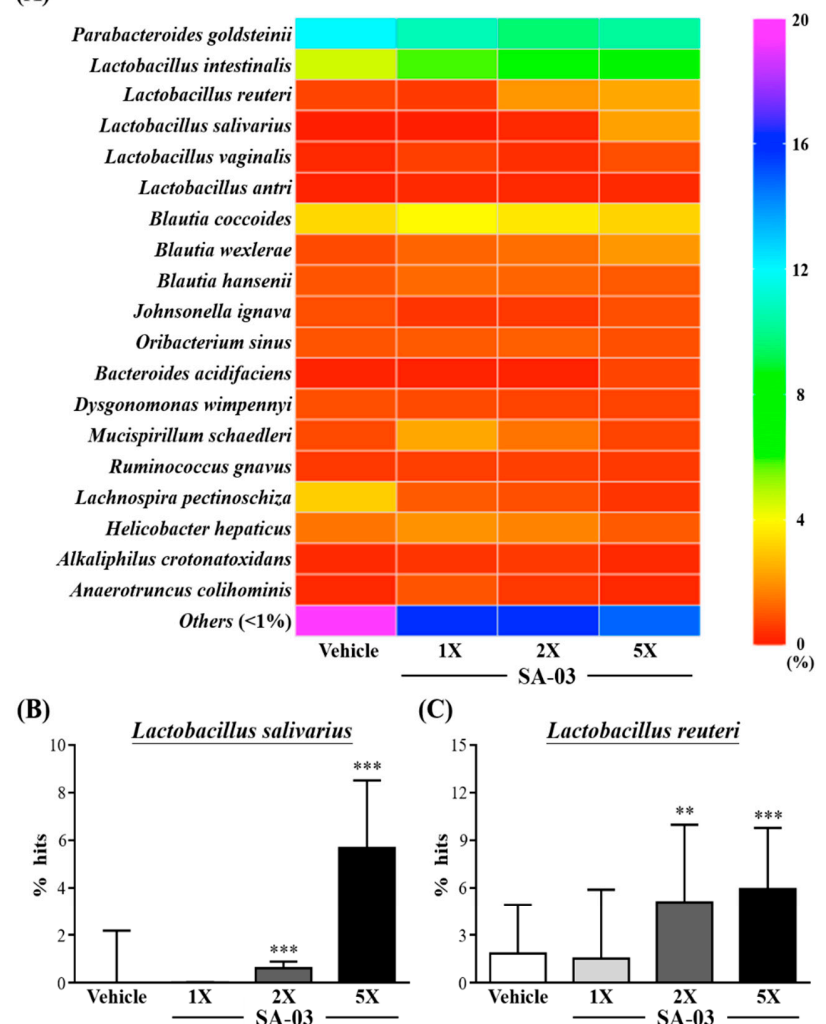

(C)
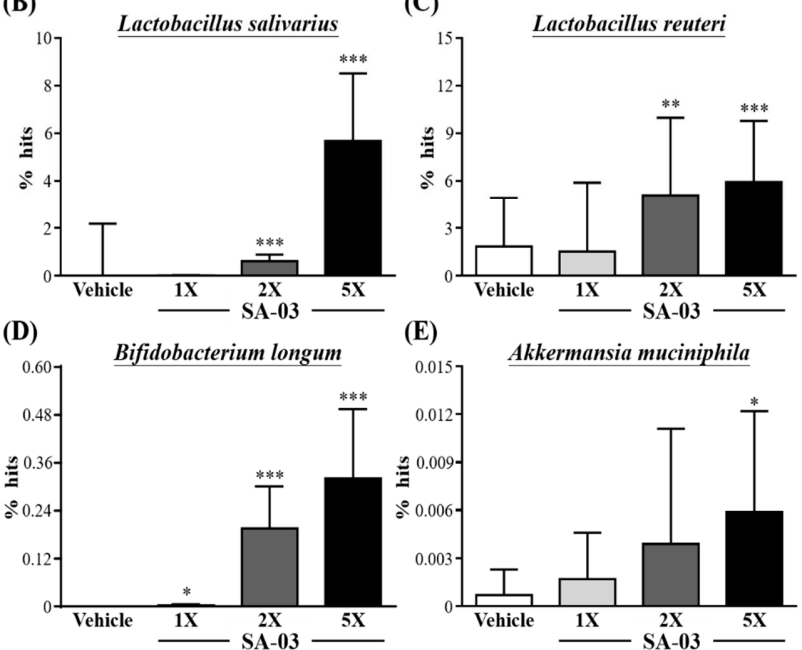

(E)

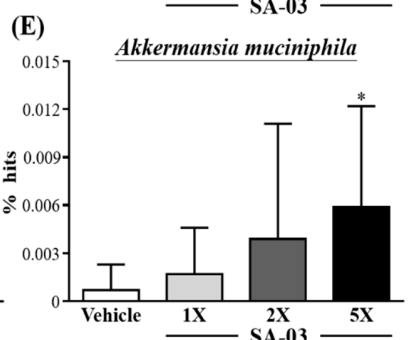

Figure 8. Effect of 4 weeks of SA-03 supplementation on (A) Species heatmap of gut microbiota, (B) Lactobacillus salivarius \% hit, (C) Lactobacillus reuteri \% hit, (D) Bifidobacterium longum \% hit and (E) Akkermansia muciniphila \% hit. Data are expressed as mean \pm SD for $n=9$ mice per group. Values with different superscript letters are significantly different at ${ }^{*}, p<0.05 ;{ }^{* *}, p<0.05 ;{ }^{* * *}, p<0.05$ by $t$-test. 
Compared with vehicle group, the Lactobacillus salivarius (Figure 8B) in Sa-03-1X, SA-03-2X and SA-03-5X were significantly increased and the percentage were changes by $0.01 \%, 0.61 \%$ and $5.68 \%$ $(p<0.001)$, respectively. The abundance of Lactobacillus reuteri (Figure $8 \mathrm{C}$ ) also significantly increased in SA-03-2x and SA-03-5x $(p<0.01) 3.27 \%$ and $4.11 \%$ percentage changes, respectively. In particular, in addition to the significantly increased in the richness of lactobacillus by SA-03 supplementation, Bifidobacterium longum (Figure 8D) and Akkermansia muciniphila (Figure 8E) percentage of gut microbiota were significantly richer than vehicle group $(p<0.05)$. In addition, among the human harmful gut microbiota, the Helicobacter hepaticus was significantly lower in the SA-03-5X group than vehicle group, from $3.74 \%$ to $2.64 \%(p<0.05)$.

\subsection{Effect of SA-03 Supplementation on Tissue Histology}

At the end of the study, histological examinations of liver, muscle, heart, kidney, lung, EFP and BAT of mice were performed, and no abnormalities were observed among all groups (Figure 9). There was also no difference in the morphology of adipose tissue and fat cell size among the groups. These results indicate that SA-03 does not have adverse effects on organs and tissues at the doses tested in this study.
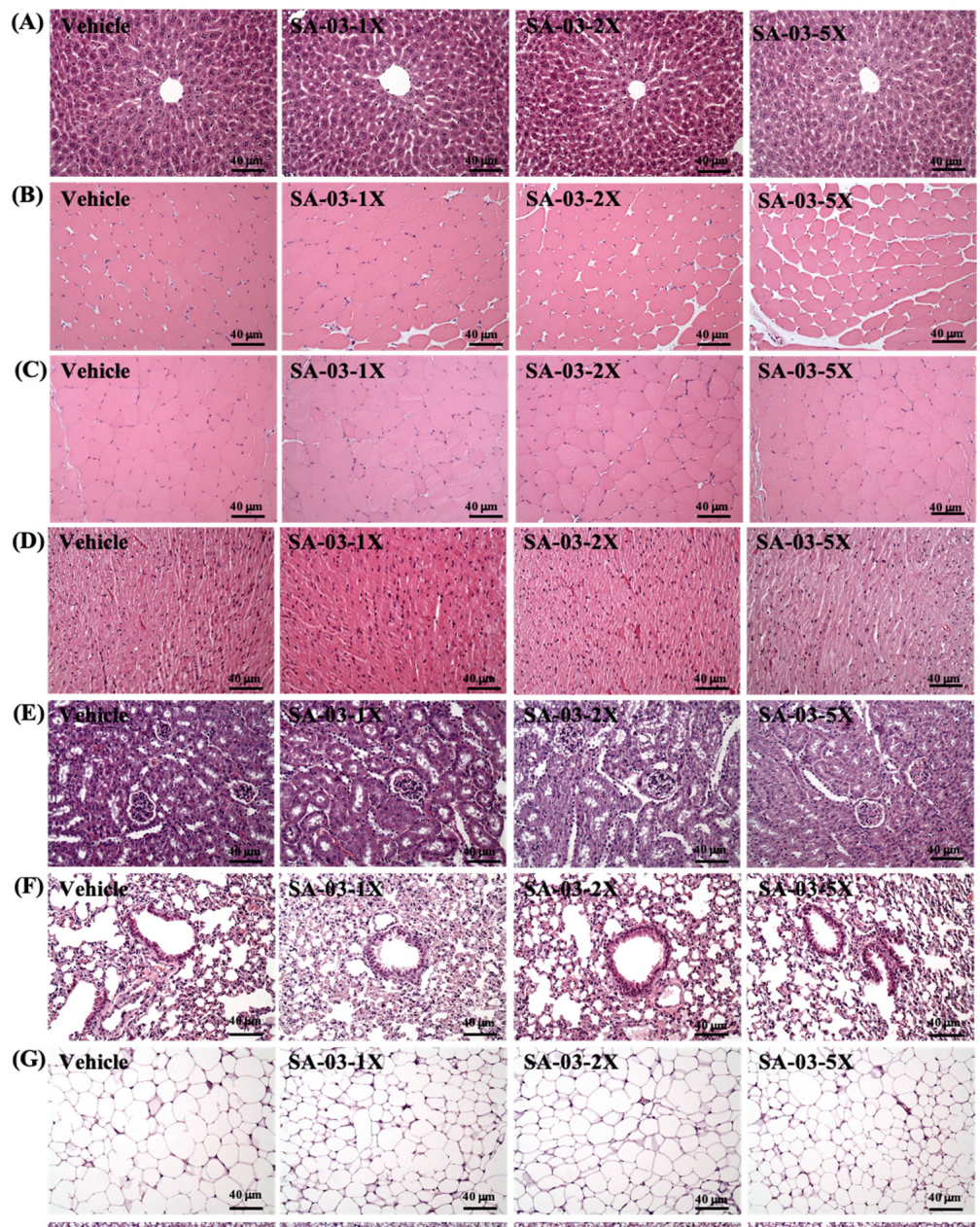

SA-03-2X
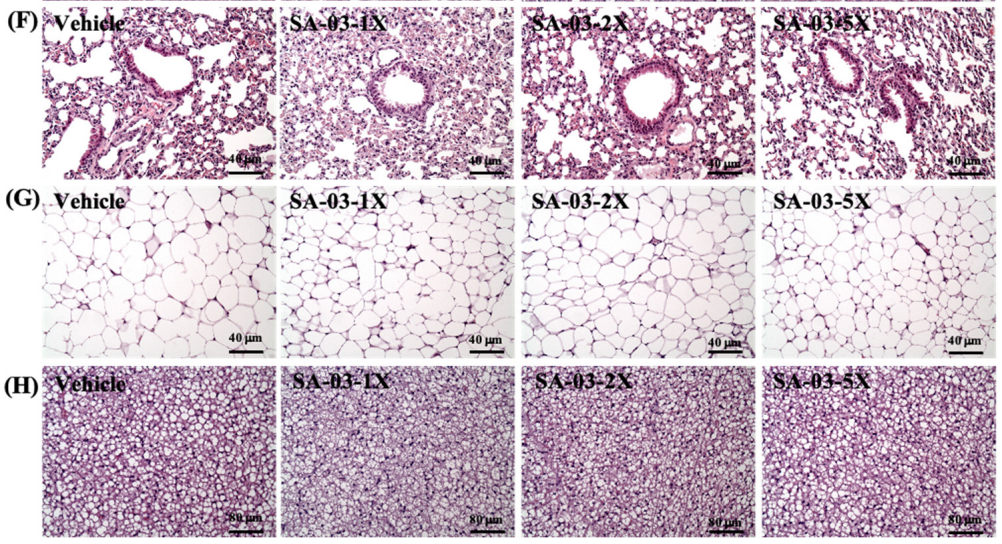

Figure 9. Effect of SA-03 supplementation on (A) liver, (B) muscle, (C) quadricep muscles, (D) heart, (E) kidney, (F) lung, (G) adipocyte tissue, and (H) BAT tissue in mice. (H\&E stain, magnification: 200x; bar, $40 \mu \mathrm{m}$; BAT magnification: 100x; bar, $80 \mu \mathrm{m}$ ). 


\section{Discussion}

Although different strains have different efficacy characteristics, research specifically designed to investigate the effect of probiotic supplementation on performance is still uncommon. Recent studies have shown that probiotic supplements can improve athletic performance in various ways through athletes and individuals who exercise with discrete probiotic strains and pointed out that they could effectively improve exercise performance and reduce fatigue indicators [27]. However, the probiotic effect may relate to the strain, dose, period consumption or even the form of administration (capsules, sachets or fermented milk) [5]. Therefore, we used the recommended human dose of $1 \times 10^{10} \mathrm{CFU} / \mathrm{day}$ as 1 times dose [22] and following required by the anti-fatigue health food regulations established by the Taiwan Ministry of Health and Welfare to design the 1, 2, and 5 times doses used in this study. Four weeks of L. salivarius (SA-03) supplementation was found to significantly improve muscle strength and weight-loading swimming endurance, reduce serum levels of fatigue indicators (lactate, BUN, ammonia, and CK), and increase liver and muscle glycogen content. SA-03 was also found to have no effects on organs and tissues.

There is a close relationship between changes in intestinal microorganisms and athletic performance. Several studies have found that that athletes have increased intestinal microbial diversity compared to non-athletes [28-30]. Moreover, another study has also been observed that exercise is directly proportional to the abundance of pathways, which in turn is related to the increased branched chain amino acid (BCAA) pathway [28], which is important for muscle recovery and increase in Methanobrevibacter smithii, a microorganism that uses $\mathrm{H}_{2}$ in the colon to produce SCFA and ATP [29]. Therefore, it seems reasonable that probiotics can improve athletic performance through the action of probiotics, because athletes can delay fatigue by producing SCFA. In this study, we found that four weeks of SA-03 supplementation significantly decreased one of the fatigue indexes, lactate (Table 2), probably by expediting its conversion to butyrate and then to acetyl-CoA, which is used in the Krebs Cycle to generate ATP [31]. SA-03 supplementation was also found to reduce serum levels of another fatigue indicator, ammonia which is a waste of amino acids metabolism [32]. When starvation or exercise reduces glucose levels, skeletal muscle would metabolize amino acids to generate energy. As a result, ammonia is produced and released to blood or excreted to the urine [33]. This would cause fatigue and reduce exercise performance. A previous study showed that probiotics can decrease intestinal permeability, inhibit bacterial urease activity to reduce ammonia in blood, and increase the levels of lactic acid [34]. Since lactic acid can decrease the $\mathrm{pH}$ of the intestine, ammonia absorption is reduced. Probiotics have been shown to reduce inflammation and oxidative stress in liver cells, thus increased liver clearance of ammonia and other toxins [35]. Similar result as this study, SA-03 Supplementation could effectively reduce blood ammonia caused by exercise and increase glucose in the blood as energy (Figure 4A,B), and also includes two other fatigue and injury indicators, BUN and CK (Figure 5A,B), which could be significantly reduced by supplementing SA-03. Therefore, we confirm that supplementation with SA-03 can reduce fatigue and injury after exercise.

The gut microbiota and SCFA metabolites may reduce colonic mucosal permeability and inhibit inflammatory cytokines. Previous study was shown that probiotic supplementation significantly reduced serum concentrations of pro-inflammatory cytokines including, high-sensitivity CRP (hs-CRP), tumor necrosis factor $\alpha$ (TNF- $\alpha$ ), interleukin (IL)-6, IL-12, and significant increase in serum levels of IL-10, as anti-inflammatory cytokine [36]. These anti-inflammatory effects may help delay fatigue symptoms in endurance performance [4]. In recent years, the functional contribution of gut-muscle axis has received more and more attention. Butyrate may have activation of multiple regulatory pathways, in addition to its anti-inflammatory properties, it can also increase ATP production and improve the metabolic efficiency of muscle fibers [37,38]. A previous study has shown that taking butyrate in aging mice has the ability to inhibit histone deacetylase, thereby improving effects such as lean muscle mass and cross-sectional area [39]. Although this difference may not be seen in this study because we used young mice (Figure 9B), this argument deserves an important reference for future studies on SA-03 with regard to sarcopenia. 
Among the 26 studies we found in the literature on the effects of evaluating probiotics on exercise endurance, 17 showed no effects and nine reported significant improvements. In some studies, multiple probiotics were added to increase maximum oxygen uptake, aerobic capacity, training load, and increase physical exertion time, only a few studies point to single-strain probiotic supplementation has produced a significant aerobic performance benefit [27]. Previous studies have shown that supplementation of Saccharomyces boulardii in rats undergoing accelerated exercise increased maximum oxygen consumption by $12.7 \%$, maximum aerobic speed by $12.4 \%$, and running time to fatigue by $21.6 \%$, compared to with sedentary the control group [40]. In our previous study, the Bifidobacterium longum (OLP-01) isolated from a weightlifting gold medalist found that, not only help in fatigue indicators, but also significantly increased 1.77-3.37-fold exercise to exhaustive time by $1 \mathrm{X}, 2 \mathrm{X}$ and $5 \mathrm{X}$ dose OLP-01 supplementation for four weeks, in addition, it also has a significant increase in forelimb grip, although there is no significant difference in muscle mass [16]. Lactobacillus plantarum (TWK10) supplement not only improves exercise performance and increases muscle mass in mice [15], but also increased endurance performance and elevated blood glucose concentration following exercise-to-exhaustion after six weeks of high dose $\left(1 \times 10^{11} \mathrm{CFU}\right)$ TWK10 supplementation in untrained healthy male adults [41]. Four weeks of SA-03 supplementation significantly increased the time from swimming endurance to exhaustion in mice (Figure 2) and increased forelimb grip (Figure 3). Although we all know that probiotic supplementation can significantly increase SCFA and use fatty acid oxidation and activate peroxisome proliferator-activated receptor gamma coactivator- $1 \alpha$ (PGC-1 $\alpha$ ) to generate more ATP for the energy required for exercise, and improve exercise performance and increase endurance [14,42], however, SA-03 need to be further studied as functioning auxiliary agents to enhance their functions, and may be obtained indirectly by regulating other systems.

Glycogen is a multi-branched glucose homopolysaccharide, a common form of energy storage in animals and eukaryotic microorganisms [43]. There is a high correlation between glycogen storage and carbohydrate uptake and metabolism [44]. In the intestine, carbohydrates are absorbed and converted to SCFA, such as n-butyric acid, acetic acid, and propionic acid. Propionic acid contributes to liver glycogen production [45]. As shown in Figure 6A,B, SA-03 Supplementation increased glycogen storage in liver and muscle.

At present, probiotics are used in society as a nutritional supplement. In our study, we not only explored the performance, but also observed the animal's pathological sections and serum biochemical values at the end of the experiment. Any obvious abnormalities or obvious lesions found in various tissues will not cause any discomfort and damage to the individual. The strains selected in this research are selected from human body, and it is hoped that in the future, human experiments will be used to determine the efficacy of applying to human, which can provide exercise groups or competitive players to help improve exercise performance and capability.

\section{Conclusions}

In the present study, we found that four weeks of supplementation with SA-03 (Lactobacillus salivarius), a bacterial strain isolated from a weightlifting gold medalist, significantly changed the gut microbiota. Interestingly, in addition to the increased abundance of Lactobacillus salivarius in the SA-03 groups, the number of Lactobacillus reuteri also increased significantly, and to made significantly decreased the levels of fatigue indicators such as lactate, BUN, ammonia, and CK. SA-03 was also found to increase muscle strength, endurance performance, and glycogen storage in liver and muscle cells. These results suggest that SA- 03 could be used as a supplement to enhance exercise performance and mitigating fatigue. Further studies are warranted to understand the mechanisms of action of SA-03.

Author Contributions: H.-H.H., H.-C.S. and C.-C.H. designed the study. M.-C.L., Y.-J.H., S.-H.H., and Y.-W.K. carried out the experiments. H.-H.H., H.-C.S. and C.-C.H. provided reagents and other lab supplies. M.-C.L., Y.-J.H., S.-H.H., Y.-W.K. and C.-C.H. analyzed the data. M.-C.L., H.-C.S. and C.-C.H. prepared figures and wrote the manuscript. All authors have read and agree to the published version of the manuscript. 
Funding: This study was funded by the University-Industry Cooperation Fund (NTSU No.1081041), National Taiwan Sport University, Taoyuan, Taiwan.

Acknowledgments: We thank Chin-Shan Ho for assistance in measuring forelimb grip strength, Chien-Chao Chiu for performing histological examinations, coach Wei-Ling Chen for providing her valuable gut microbiota, Glac Biotech Co., Ltd. (Tainan City, Taiwan) for providing the probiotics, and Yao-Tsung Yeh (Aging and Disease Prevention Research Center, Fooyin University, Kaohsiung, Taiwan) for gut microbiota analysis.

Conflicts of Interest: The authors declare no conflict of interest.

\section{References}

1. Davis, J.M. Central and peripheral factors in fatigue. J. Sports Sci. 1995, 13, S49-S53. [CrossRef] [PubMed]

2. Zając, A.; Chalimoniuk, M.; Gołaś, A.; Lngfort, J.; Maszczyk, A. Central and peripheral fatigue during resistance exercise-A critical review. J. Hum. Kinet. 2015, 49, 159-169. [CrossRef] [PubMed]

3. Wan, J.J.; Qin, Z.; Wang, P.Y.; Sun, Y.; Liu, X. Muscle fatigue: general understanding and treatment. Exp Mol. Med. 2017, 49, e384. [CrossRef] [PubMed]

4. Mach, N.; Fuster-Botella, D. Endurance exercise and gut microbiota: A review. J. Sport Health Sci. 2017, 6, 179-197. [CrossRef] [PubMed]

5. Leite, G.S.F.; Resende, A.S.; West, N.P.; Lancha, A.H., Jr. Probiotics and sports: A new magic bullet? Nutrition 2019, 60, 152-160. [CrossRef] [PubMed]

6. Food and Agriculture Organization of the United Nations; World Health Organization. Guidelines for the Evaluation of Probiotics in Food. In Proceedings of the Joint FAO/WHO Working Group Report on Drafting Guidelines for the Evaluation of Probiotics in Food, London, ON, Canada, 30 April-1 May 2002.

7. Sivamaruthi, B.S.; Kesika, P.; Suganthy, N.; Chaiyasut, C. A Review on Role of Microbiome in Obesity and Antiobesity Properties of Probiotic Supplements. Biomed. Res. Int. 2019, 2019, 3291367. [CrossRef] [PubMed]

8. Huang, W.C.; Chen, Y.M.; Kan, N.W.; Ho, C.S.; Wei, L.; Chan, C.H.; Huang, C.C. Hypolipidemic Effects and Safety of Lactobacillus Reuteri 263 in a Hamster Model of Hyperlipidemia. Nutrients 2015, 7, 3767-3782. [CrossRef]

9. Sichetti, M.; De Marco, S.; Pagiotti, R.; Traina, G.; Pietrella, D. Anti-inflammatory effect of multistrain probiotic formulation (L. rhamnosus, B. lactis, and B. longum). Nutrition 2018, 53, 95-102. [CrossRef]

10. Kang, M.S.; Lim, H.S.; Oh, J.S.; Lim, Y.J.; Wuertz-Kozak, K.; Harro, J.M.; Shirtliff, M.E.; Achermann, Y. Antimicrobial activity of Lactobacillus salivarius and Lactobacillus fermentum against Staphylococcus aureus. Pathog. Dis. 2017, 75, 2. [CrossRef]

11. Pourramezan, Z.; Kasra Kermanshahi, R.; Oloomi, M.; Aliahmadi, A.; Rezadoost, H. In vitro study of antioxidant and antibacterial activities of Lactobacillus probiotic spp. Folia Microbiol. (Praha) 2018, 63, 31-42. [CrossRef]

12. Tiptiri-Kourpeti, A.; Spyridopoulou, K.; Santarmaki, V.; Aindelis, G.; Tompoulidou, E.; Lamprianidou, E.E.; Saxami, G.; Ypsilantis, P.; Lampri, E.S.; Simopoulos, C.; et al. Lactobacillus casei exerts anti-proliferative effects accompanied by apoptotic cell death and up-regulation of TRAIL in colon carcinoma cells. PLoS ONE 2016, 11, e0147960. [CrossRef] [PubMed]

13. Nagpal, R.; Wang, S.; Ahmadi, S.; Hayes, J.; Gagliano, J.; Subashchandrabose, S.; Kitzman, D.W.; Becton, T.; Read, R.; Yadav, H. Human-origin probiotic cocktail increases short-chain fatty acid production via modulation of mice and human gut microbiome. Sci. Rep. 2018, 8, 12649. [CrossRef] [PubMed]

14. Clark, A.; Mach, N. The Crosstalk between the Gut Microbiota and Mitochondria during Exercise. Front. Physiol. 2017, 8, 319. [CrossRef] [PubMed]

15. Chen, Y.M.; Wei, L.; Chiu, Y.S.; Hsu, Y.J.; Tsai, T.Y.; Wang, M.F.; Huang, C.C. Lactobacillus plantarum TWK10 Supplementation Improves Exercise Performance and Increases Muscle Mass in Mice. Nutrients 2016, 8, 205. [CrossRef] [PubMed]

16. Lee, M.C.; Hsu, Y.J.; Chuang, H.L.; Hsieh, P.S.; Ho, H.H.; Chen, W.L.; Chiu, Y.S.; Huang, C.C. In Vivo Ergogenic Properties of the Bifidobacterium longum OLP-01 Isolated from a Weightlifting Gold Medalist. Nutrients 2019, 11, 2003. [CrossRef]

17. Rogosa, M.; Wiseman, R.F.; Mitchell, J.A.; Disraely, M.N.; Beaman, A.J. Species differentiation of oral lactobacilli from man including descriptions of Lactobacillus salivarius nov spec and Lactobacillus cellobiosus nov spec. J. Bacteriol. 1953, 65, 681-699. [CrossRef] 
18. Claesson, M.J.; Li, Y.; Leahy, S.; Canchaya, C.; van Pijkeren, J.P.; Cerdeño-Tárraga, A.M.; Parkhill, J.; Flynn, S.; O'Sullivan, G.C.; Collins, J.K.; et al. Multireplicon genome architecture of Lactobacillus salivarius. Proc. Natl. Acad. Sci. USA 2006, 103, 6718-6723. [CrossRef]

19. Raftis, E.J.; Salvetti, E.; Torriani, S.; Felis, G.E.; O’Toole, P.W. Genomic diversity of Lactobacillus salivarius. J. Bacteriol. 2011, 77, 954-965.

20. Neville, B.A.; O’Toole, P.W. Probiotic properties of Lactobacillus salivarius and closely related Lactobacillus species. Future Microbiol. 2010, 5, 759-774. [CrossRef]

21. Axelrod, C.L.; Brennan, C.J.; Cresci, G.; Paul, D.; Hull, M.; Fealy, C.E.; Kirwan, J.P. UCC118 supplementation reduces exercise-induced gastrointestinal permeability and remodels the gut microbiome in healthy humans. Physiol. Rep. 2019, 7, e14276. [CrossRef]

22. Maughan, R.J.; Burke, L.M.; Dvorak, J.; Larson-Meyer, D.E.; Peeling, P.; Phillips, S.M.; Rawson, E.S.; Walsh, N.P.; Garthe, I.; Geyer, H.; et al. IOC consensus statement: dietary supplements and the high-performance athlete. Br. J. Sports Med. 2018, 52, 439-455. [CrossRef] [PubMed]

23. Wu, R.E.; Huang, W.C.; Liao, C.C.; Chang, Y.K.; Kan, N.W.; Huang, C.C. Resveratrol protects against physical fatigue and improves exercise performance in mice. Molecules 2013, 18, 4689-4702. [CrossRef] [PubMed]

24. Huang, W.C.; Huang, H.Y.; Hsu, Y.J.; Su, W.H.; Shen, S.Y.; Lee, M.C.; Lin, C.L.; Huang, C.C. The Effects of Thiamine Tetrahydrofurfuryl Disulfide on Physiological Adaption and Exercise Performance Improvement. Nutrients 2018, 10, 851. [CrossRef] [PubMed]

25. Huang, S.W.; Hsu, Y.J.; Lee, M.C.; Li, H.S.; Yeo, P.C.W.; Lim, A.L.; Huang, C.C. In Vitro and In Vivo Functional Characterization of Essence of Chicken as An Ergogenic Aid. Nutrients. Nutrients 2018, 10, 1943. [CrossRef] [PubMed]

26. Hsu, Y.J.; Huang, W.C.; Lin, J.S.; Chen, Y.M.; Ho, S.T.; Huang, C.C.; Tung, Y.T. Kefir Supplementation Modifies Gut Microbiota Composition, Reduces Physical Fatigue, and Improves Exercise Performance in Mice. Nutrients 2018, 10, 862. [CrossRef] [PubMed]

27. Jäger, R.; Mohr, A.E.; Carpenter, K.C.; Kerksick, C.M.; Purpura, M.; Moussa, A.; Townsend, J.R.; Lamprecht, M.; West, N.P.; Black, K.; et al. International Society of Sports Nutrition Position Stand: Probiotics. J. Int. Soc. Sports Nutr. 2019, 16, 62. [CrossRef]

28. Barton, W.; Penney, N.C.; Cronin, O.; Garcia-Perez, I.; Molloy, M.G.; Holmes, E.; Shanahan, F.; Cotter, P.D.; O'Sullivan, O. The microbiome of professional athletes differs from that of more sedentary subjects in composition and particularly at the functional metabolic level. Gut 2018, 67, 625-633. [CrossRef]

29. Petersen, L.M.; Bautista, E.J.; Nguyen, H.; Hanson, B.M.; Chen, L.; Lek, S.H.; Sodergren, E.; Weinstock, G.M. Community characteristics of the gut microbiomes of competitive cyclists. Microbiome 2017, 5, 98. [CrossRef]

30. Clarke, S.F.; Murphy, E.F.; O’Sullivan, O.; Lucey, A.J.; Humphreys, M.; Hogan, A.; Hayes, P.; O’Reilly, M.; Jeffery, I.B.; Wood-Martin, R.; et al. Exercise and associated dietary extremes impact on gut microbial diversity. Gut 2014, 63, 1913-1920. [CrossRef]

31. Coqueiro, A.Y.; de Oliveira Garcia, A.B.; Rogero, M.M.; Tirapegui, J. Probiotic supplementation in sports and physical exercise: Does it present any ergogenic effect? Nutr. Health. 2017, 23, 239-249. [CrossRef]

32. Bachmann, C. Mechanisms of hyperammonemia. Clin. Chem. Lab. Med. 2002, 40, 653-662. [CrossRef] [PubMed]

33. Norenberg, M.D.; Rao, K.V.; Jayakumar, A.R. Mechanisms of ammonia-induced astrocyte swelling. Metab. Brain Dis. 2005, 20, 303-318. [CrossRef] [PubMed]

34. Bongaerts, G.; Severijnen, R.; Timmerman, H. Effect of antibiotics, prebiotics and probiotics in treatment for hepatic encephalopathy. Med. Hypotheses 2005, 64, 64-68. [CrossRef] [PubMed]

35. Liu, J.; Lkhagva, E.; Chung, H.J.; Kim, H.J.; Hong, S.T. The Pharmabiotic Approach to Treat Hyperammonemia. Nutrients 2018, 10, 140. [CrossRef] [PubMed]

36. Milajerdi, A.; Mousavi, S.M.; Sadeghi, A.; Salari-Moghaddam, A.; Parohan, M.; Larijani, B.; Esmaillzadeh, A. The effect of probiotics on inflammatory biomarkers: A meta-analysis of randomized clinical trials. Eur. J. Nutr. 2020, 59, 633-649. [CrossRef]

37. Leonel, A.J.; Alvarez-Leite, J.I. Butyrate: implications for intestinal function. Curr. Opin. Clin. Nutr. Metab. Care 2012, 15, 474-479. [CrossRef] 
38. Den Besten, G.; Gerding, A.; van Dijk, T.H.; Ciapaite, J.; Bleeker, A.; van Eunen, K.; Havinga, R.; Groen, A.K.; Reijngoud, D.J.; Bakker, B.M. Protection against the Metabolic Syndrome by Guar Gum-Derived Short-Chain Fatty Acids Depends on Peroxisome Proliferator-Activated Receptor $\gamma$ and Glucagon-Like Peptide-1. PLoS ONE 2015, 10, e0136364. [CrossRef]

39. Walsh, M.E.; Bhattacharya, A.; Sataranatarajan, K.; Qaisar, R.; Sloane, L.; Rahman, M.M.; Kinter, M.; Van Remmen, H. The histone deacetylase inhibitor butyrate improves metabolism and reduces muscle atrophy during aging. Aging Cell 2015, 14, 957-970. [CrossRef]

40. Soares, A.D.N.; Wanner, S.P.; Morais, E.S.S.; Hudson, A.S.R.; Martins, F.S.; Cardoso, V.N. Supplementation with Saccharomyces boulardii Increases the Maximal Oxygen Consumption and Maximal Aerobic Speed Attained by Rats Subjected to an Incremental-Speed Exercise. Nutrients 2019, 11, 2352. [CrossRef]

41. Huang, W.C.; Lee, M.C.; Lee, C.C.; Ng, K.S.; Hsu, Y.J.; Tsai, T.Y.; Young, S.L.; Lin, J.S.; Huang, C.C. Effect of Lactobacillus plantarum TWK10 on Exercise Physiological Adaptation, Performance, and Body Composition in Healthy Humans. Nutrients 2019, 11, 2836. [CrossRef]

42. Al-Obaidi, S.; Al-Sayegh, N.; Nadar, M. Smoking impact on grip strength and fatigue resistance: Implications for exercise and hand therapy practice. J. Phys. Act. Health 2014, 11, 1025-1031. [PubMed]

43. Goh, Y.J.; Klaenhammer, T.R. Insights into glycogen metabolism in Lactobacillus acidophilus: Impact on carbohydrate metabolism, stress tolerance and gut retention. Microb. Cell Fact. 2014, 13, 94. [CrossRef] [PubMed]

44. Hearris, M.A.; Hammond, K.M.; Fell, J.M.; Morton, J.P. Regulation of Muscle Glycogen Metabolism during Exercise: Implications for Endurance Performance and Training Adaptations. Nutrients 2018, 10, 298. [CrossRef] [PubMed]

45. Samuel, B.S.; Shaito, A.; Motoike, T.; Rey, F.E.; Backhed, F.; Manchester, J.K.; Hammer, R.E.; Williams, S.C.; Crowley, J.; Yanagisawa, M.; et al. Effects of the gut microbiota on host adiposity are modulated by the short-chain fatty-acid binding G protein-coupled receptor, Gpr41. Proc. Natl. Acad. Sci. USA 2008, 105, 16767-16772. [CrossRef] [PubMed]

(C) 2020 by the authors. Licensee MDPI, Basel, Switzerland. This article is an open access article distributed under the terms and conditions of the Creative Commons Attribution (CC BY) license (http://creativecommons.org/licenses/by/4.0/). 